\title{
СУДЕБНЫЕ ПОЛНОМОЧИЯ ПАЛАТЫ ЛОРДОВ. ИСТОРИЯ ИХ ЭВОЛЮЦИИ И ЗАКОНОДАТЕЛЬНОГО РЕГУЛИРОВАНИЯ
}

\begin{abstract}
Аннотация: В статье исследуются исторические и юридические причины возникновения и длительного совмещения Палатой лордов британского Парламента законотворческих и судебных полномочий, что не соответствовало общепризнанным представлениям о демократии и вступало в противоречие с принципом разделения властей. Анализируются основные этапы развития судебных прерогатив пэров, рассматриваются факторы, диктовавшие необходимость их статутного регулирования и закрепления. Отдельное внимание уделено Акту о конституционной реформе 2005 г., следствием которого стало фактическое преобразование Апелляционного комитета Палаты лордов в новый структурный элемент судебной системы Соединенного королевства - Верховный суд.
\end{abstract}

Ключевые слова: Политология, ЕврАзЭС, Таможенный союз, Россия, ЕЭП, Наднациональный орган, Сотрудничество, ВТО, ОДКБ, ШОС

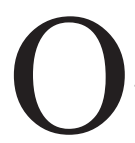
собенности исторического развития Великобритании, ее определенная изолированность от континентальной Европы, вызванная островным характером государства, стали причиной возникновения целого ряда уникальных государственных институтов, не имевших аналогов в других странах. В частности, иностранцев всегда поражала, сложная и запутанная английская судебная система. Как справедливо отмечал в своей книге известный британский юрист и лейбористский политик Питер Арчер: «Судебная система Англии полна неожиданностей. Она не поддается никакой научной классификации и даже те, кто посвятил служению ей всю свою жизнь, не претендуют на то, что они постигли ее во всех деталях». ${ }^{1}$

Согласно британской конституционной доктрине, осуществление правосудия в королевстве является прерогативой монарха, которую он реализует при помощи должным образом назначенных судей и судебных органов. При этом вся эта система формировалась естественным образом. Тот или иной суд в стране возникал только тогда, когда необходимость в нем становилась объективной реальностью, а не в результате заранее продуманного и реализованного проекта. Во многом это является следствием действующей в Великобритании системы прецедентного права, нормы которого берутся из основной части решений, вынесен-

\footnotetext{
${ }^{1}$ Арчер П. Английская судебная система. - М., 1959. - С.26.
}

ных высшими судебными инстанциями. Роль таких судов, бесспорно, является центральной, поскольку именно они создают прецеденты, на которые ориентируются все судьи при рассмотрении новых дел. Удивительной особенностью английской судебной системы было то, что вплоть до недавнего времени функция последней, окончательной инстанции принадлежала Палате лордов, составной части британского Парламента. Принцип разделения властей, сформулированный отцом европейского Просвещения Джоном Локком в самой Великобритании, таким образом, вопиюще нарушался, поскольку одни и те же люди выступали и в качестве судей и в роли творцов законов.

Происхождение судебных полномочий британской Палаты лордов имеет очень давнюю историю. Большинство историков считает, что эту функцию она унаследовала от предшественника Парламента - Королевского совета, консультативного органа раннего Средневековья, сочетавшего в своей деятельности законодательные, исполнительные и судебные полномочия. Произошедшее в ХІІІ в. преобразование Королевского совета в Парламент, привело и к передаче в его ведение роли высшего королевского суда. Примечательно, что судьями Высокого суда Парламента в тот период времени были не только пэры, но и выборные представители городов и графств. Только после разделения английского Парламента в XIV в. на Палату общин и Палату лордов судебные полномочия оказались в руках родовитой аристократии. Последний случай 
DOI: $10.7256 / 1812-8696.2013 .05 .15$

История права

участия представителей нижней палаты в судебном заседании был отмечен в 1399 г. ${ }^{2}$ В следующем году, депутаты Палаты общин даже приняли специальную петицию, в которой просили монарха освободить их от выполнения судебных обязанностей. ${ }^{3}$

Долгое время все вопросы, связанные с исполнением пэрами роли судей, регулировались в основном традициями и судебными прецедентами, что объясняется уже упоминавшимися особенностями английской правовой системы, имеющей в своей основе обычное общее право. Статутное регулирование этой сферы деятельности было явлением достаточно редким и, даже можно сказать, исключительным. Самый известный его пример относится к периоду правления королевы Елизаветы I Тюдор. Акт об ошибочных решениях Суда королевской скамьи 1584 г. и Акт об ошибочных судебных решениях 1588 г. законодательно закрепили фактически существовавшее право Палаты лордов рассматривать апелляции из нижестоящих судов. ${ }^{4}$

Несмотря на имевшиеся единичные примеры регулирования статутами судебных функций Палаты лордов, можно утверждать, что до последней трети XIX в. в Великобритании отсутствовала серьёзная законодательная база в этой сфере. При этом верхняя палата Парламента к этому моменту обладала достаточно обширными судебными полномочиями. По первой инстанции она была вправе рассматривать дела, возбуждённые против пэров, а также дела, в которых оспаривались привилегии самой палаты. В Палате лордов инициировались в порядке импичмента дела об индивидуальной ответственности высших должностных лиц государства. Выступая в качестве высшей апелляционной инстанции Соединённого королевства, Палата лордов рассматривала жалобы на решения по уголовным и гражданским делам, поступившие из нижестоящих судов Англии, Уэльса и Ирландии, а также по гражданским делам из судов Шотландии.

Начало законодательного регулирования судебных прерогатив верхней палаты Парламента непосредственно связано с разработкой по инициативе Кабинета Б. Дизраэли масштабной судебной реформы, призванной приспособить британские органы правосудия

\footnotetext{
${ }^{2}$ House of Lords Briefing. The Judicial Work of the House of Lords. - L., 2005. - P.1

${ }^{3}$ Арчер П. Указ. соч. - С. 98.

${ }^{4}$ Powell J.E. Wallis K. The House of Lords in the Middle Ages. - L., 1968. -578.
}

к реалиям поздневикторианской эпохи. Примечательно, что в рамках планировавшейся модернизации, политики даже обсуждали возможность полной ликвидации апелляционных функций Палаты лордов. Однако в последний момент консервативное правительство Б.Дизраэли передумало и отказалось от этой радикальной идеи. Вместо этого тори в 1876 г. провели через Парламент Акт об апелляционной юрисдикции. В этом документе (статьи 3 и 4 - И.К) не только подтверждалось, но и законодательно закреплялось право Палаты лордов рассматривать апелляции на решения высших судов Англии, Уэльса и Ирландии по уголовным и гражданским делам, а также судов Шотландии по гражданским делам. ${ }^{5}$

Принципиально важная новая статутная норма содержалась в пятой статье данного закона. В ней говорилось, что «ни одна жалоба не может рассматриваться в Палате лордов, если при изучении петиции о подаче апелляции не присутствовали, по крайней мере, три судебных лорда». ${ }^{6}$ К числу последних согласно Акту об апелляционной юрисдикции 1876 г. относились: лорд-канцлер, ординарные лорды по апелляциям, которых еще предстояло назначить, а также пэры, которые занимали ранее высшие судейские должности или продолжали осуществлять правосудие. Суть понятия «высшие судейские должности» специально расшифровывалось в двадцать пятой статье данного акта. Авторы статута включили в их число сотрудников офиса лорд-канцлера, всех судей Высокого суда, Апелляционного суда Англии и Уэльса, а также Сессионного суда Шотландии. ${ }^{7}$

Отказавшись от слишком радикальной идеи лишения Палаты лордов права рассматривать жалобы на решения нижестоящих судов, торийские политики попытались добиться повышения качества рассмотрения апелляционных дел в верхней палате за счет передачи их в ведение исключительно профессиональных юристов. Стоит напомнить, что в период Средневековья при рассмотрении подобных дел мог принимать участие любой пэр. Однако, уже в течении XVIII в. постепенно в практику вошла новая традиция, согласно которой члены верхней палаты, не имевшие профессиональной юридической подготовки, не принимали участия в разбирательстве судеб-

\footnotetext{
${ }^{5}$ Appellate Jurisdiction Act 1876 // URL: http://www.legislation. gov.uk/ukpga/1876/59/pdfs/ukpga_18760059_en.pdf

${ }^{6}$ Ibidem

${ }^{7}$ Ibidem.
} 


\section{Политика и общество 5 (101) • 2013}

ных дел. Как следствие, когда в 1834 г. одно из решений палаты по апелляционной жалобе было принято вообще без участия профессиональных юристов, это было оценено как вопиющий случай. Спустя десять лет при рассмотрении дела Даниэла O’Конелла, лорд-канцлер, вежливо но настойчиво пресек попытки лордов не имевших юридической квалификации принять участие в голосовании при вынесении решения. ${ }^{8}$ Вместе с тем, подобного рода инциденты со всей наглядностью демонстрировали, что необходимость формального, правового закрепления сложившейся традиции становилась все более очевидной.

Принятие Акта об апелляционной юрисдикции 1876 г. поставило непреодолимую преграду на пути любых попыток пэров непрофессионалов принять участие в процедуре апелляционного разбирательства в Палате лордов. В 1883 г., когда член верхней палаты не принадлежавший к судейскому сословию, демонстративно проголосовал при вынесении решения по апелляционной жалобе, его мнение было попросту проигнорировано лордами-судьями. ${ }^{9}$ Юридическое закрепление парламентской традиции, которую попытались нарушить аристократы, не имевшие профессиональных юридических компетенций, позволило повысить судебный авторитет верхней палаты Парламента. Теперь можно было с полным основанием утверждать, что создаваемые в ее стенах прецеденты являются результатом работы квалифицированных специалистов, обладающих необходимыми знаниями в вопросах правосудия.

Другим важным нововведением Акта об апелляционной юрисдикции 1876 г. стало положение, зафиксированное в шестой статье, о назначении сувереном, путём предоставления пожизненных титулов баронов, четырёх ординарных лордов по апелляциям. Эти профессиональные юристы инкорпорировались в состав Палаты лордов для того, чтобы оказывать помощь лорд-канцлеру при рассмотрении поступавших жалоб из нижестоящих судов. В законе специально оговаривалось, что все они должны иметь самую высокую юридическую квалификацию. В частности, претенденты на эти должности до своего назначения должны были занимать высшие судейские должности в течение не менее двух лет либо выступать в качестве практикующих барристеров на протяжении ми-

\footnotetext{
${ }^{8}$ Арчер П. Указ. соч. - С.99

${ }^{9}$ Ingman T. The English Legal Process. - Blackstone, 1996. - P. 6.
}

нимум пятнадцати лет. ${ }^{10}$ Это означало, что в Палате лордов британского Парламента появилась новая категория членов - пожизненные пэры. Их титулы и места в палате самым тесным образом были связаны с их профессиональной деятельностью и не могли быть переданы по наследству. В случае смерти одного из таких пэров-судей, монарх, даровав пожизненный титул барона, должен был назначить на освободившееся место нового юриста, соответствовавшего зафиксированным в статуте квалификационным требованиям.

Следует отметить, что после вступления в силу Акта об апелляционной юрисдикции 1876 г., количество законов, так или иначе регулировавших судебные полномочия Палаты лордов, стало постепенно, но неуклонно возрастать. Особенно много таких законов было принято в течение XX в. Причем, с их помощью закреплялись как правила и принципы формирования состава судейского корпуса, так и вопросы, связанные с юрисдикцией и процедурными особенностями осуществления правосудия. Законодатели даже, правда, всего однажды, решились на статутное ограничение судебной юрисдикции Палаты лордов. Акт об уголовной юстиции 1948 г. отменил старинное право верхней палаты Парламента выступать в качестве суда первой инстанции в делах возбуждённых против пэров. ${ }^{11}$ Это означало, что первоначальная юрисдикция пэров сократилась до минимума. В ведении Палаты лордов как суда первой инстанции остались лишь дела связанные с привилегиями этой палаты. Теоретически она была вправе разбирать и дела возбуждённые по процедуре импичмента, но на практике их не было уже более 200 лет. Последний раз пэры разбирали дело об импичменте в отношении казначея Адмиралтейства - первого виконта Мелвилла, обвиненного в хищении государственных средств, в далёком 1804 г. ${ }^{12}$

С другой стороны, в отдельных случаях имело место и законодательное расширение юрисдикции Палаты лордов. В частности, статья 65 Акта о доступе к правосудию 1999 г. отменила ранее существовавшее ограничение на рассмотрение в верхней палате Парламента жалоб на решения нижестоящих судов, связанных с незаконным заключением и содержанием под

\footnotetext{
${ }^{10}$ Appellate Jurisdiction Act 1876// URL: http://www.legislation. gov.uk/ukpga/1876/59/pdfs/ukpga_18760059_en.pdf

${ }^{11}$ Criminal Justice Act 1948 // URL: http://www.legislation.gov. uk/ukpga/1948/58/pdfs/ukpga_19480058_en.pdf

${ }^{12}$ Oonagh G. and Nerys D. Impeachment. - L., 2011. - P.2.
} 
DOI: $10.7256 / 1812-8696.2013 .05 .15$

История права

стражей. ${ }^{13}$ Тем самым к компетенции Палаты лордов были отнесены апелляции по вопросам применения знаменитого института «хабеас корпус».

Однако основное внимание, как показывает анализ британского законодательства XX в. так или иначе затрагивавшего вопросы судебных полномочий Палаты лордов, в этот период было уделено вопросам формирования судейского корпуса и процедурным правилам рассмотрения дел. Прежде всего, целая серия актов способствовала постепенному увеличению численности пожизненных ординарных лордов по апелляциям, что было вызвано постоянным ростом количества рассматриваемых в палате подобных дел. Начало этому процессу было положено в 1913 г., когда на основании норм Акта об апелляционной юрисдикции к четырём уже работавшим лордам-судьям были добавлены ещё два. В 1945 г. их стало семеро, а в $1947-9 .{ }^{14}$ Финальную точку в этом процессе поставил Акт об отправлении правосудия 1968 г., установивший, что в Палате лордов будут заседать 12 ординарных лордов по апелляциям. ${ }^{15}$

Кроме этого, в британских парламентских актах $\mathrm{XX}$ в. неуклонно расширялось понятие «высшие судейские должности», что соответственно увеличивало круг лиц для возможного назначения в ординарные лорды по апелляциям. Так, например, Акт о судопроизводстве (для Северной Ирландии) 1978 г. включил в их состав судей Высокого суда Северной Ирландии и Апелляционного суда Северной Ирландии. Акт о судах и правовом обслуживании 1990 г. к числу «высших судейских должностей» отнёс шотландских адвокатов, участвовавших в слушаниях дел в Высоком суде юстициариев и в Сессионном суде, а также членов Адвокатской коллегии Северной Ирландии, выступавших в Высоком суде Северной Ирландии. ${ }^{16}$

Законодательному регулированию подверглись и полномочия действующих лордов-судей. Акт о судейских пенсиях и отставках, принятый в 1993 г. и вступивший в силу в 1995 г., установил, что ординарные лорды по апелляциям в возрасте 70 лет должны ухо-

\footnotetext{
13 Access To Justice Act 1999 // URL: http://www.legislation. gov.uk/ukpga/1999/22/pdfs/ukpga_19990022_en.pdf

${ }^{14}$ Appellate Jurisdiction Act 1947 // URL: http://www.legislation. gov.uk/ukpga/1947/11/pdfs/ukpga_19470011_en.pdf

15 Administration of Justice Act 1968 // URL: http://www. legislation.gov.uk/ukpga/1968/5/pdfs/ukpga_19680005_en.pdf

${ }^{16}$ Courts and Legal Services Act 1990 // URL: http://www. legislation.gov.uk/ukpga/1990/41/contents
}

дить в отставку. Кроме того, в этом законе указывается, что ни одно лицо, кроме лорд-канцлера, не может участвовать в отправлении судебных функций палаты после достижения 75-летнего возраста. Однако, после прекращения выполнения судейских обязанностей и ухода в отставку, ординарные лорды по апелляциям, как обладатели пожизненных пэрских титулов, сохраняют свои места в Палате лордов и право участвовать в её заседаниях, посвящённых общим вопросам политики и законодательства. ${ }^{17}$

Вторым важным направлением в законодательном регулировании судебных полномочий Палаты лордов в XX в. стало уточнение и более детальная регламентация процедурных правил направления и рассмотрения апелляционных жалоб. Так, например, в 1934 г. Акт об отправлении правосудия (апелляции) установил, что в Палате лордов могли рассматриваться только те жалобы, которые поданы с разрешения Апелляционного суда или самой верхней палаты Парламента. ${ }^{18}$ По замыслу законодателей эта норма должна была оградить высшую судебную инстанцию Соединенного королевства от слишком большого потока апелляционных дел и позволить ее судьям сконцентрироваться на рассмотрении лишь тех жалоб, в которых затрагивались существенные правовые вопросы.

В 1960-х гг. британские парламентарии внесли очередные уточнения в порядок выдачи разрешений на подачу апелляций в Палату лордов. Согласно первой статье Закона об отправлении правосудия 1960 г. и статье 33 Акта об апелляциях по уголовным делам 1968 г. они могли выдаваться в двух случаях. Во-первых, если нижестоящий суд постановлял, что затронутый в жалобе правовой вопрос имеет важное общественное значение. Во-вторых, если нижестоящий суд и сама Палата лордов, считали, что такой вопрос заслуживает внимания ординарных лордов по апелляциям. ${ }^{19}$

Наконец, Акт об отправлении правосудия 1969 г. установил, что апелляции по гражданским и уголов-

17 Judicial Pensions and Retirement Act 1993 // URL: http://www.legislation.gov.uk/ukpga/1993/8/pdfs/ ukpga_19930008_en.pdf.

${ }^{18}$ Administration of Justice (Appeals) Act 1934 // URL: http:// www.legislation.gov.uk/ukpga/1934/40/pdfs/ukpga_19340040_ en.pdf

19 Administration of Justice Act 1960 // URL: http://www. legislation.gov.uk/ukpga/1960/65/pdfs/ukpga_19600065_ en.pdf; Criminal Appeal Act 1968 // URL: http://www. legislation.gov.uk/ukpga/1968/19/pdfs/ukpga_19680019_en.pdf 


\section{Политика и общество $5(101) \cdot 2013$}

ным делам, в которых затронут вопрос содержания закона, либо в решении которых суд связан с предыдущими решениями Палаты лордов или Апелляционного суда, могли подаваться напрямую в верхнюю палату Парламента, минуя Апелляционный суд. В этом случае применялась так называемая «обходная процедура», предусматривавшая соблюдение следующих обязательных условий. Прежде всего, судье, рассматривавшему дело, следовало установить, что оно связано с решением правового вопроса, сопряженного с толкованием закона. Кроме этого, все стороны, участвовавшие в деле, должны были выразить согласие с предлагаемым порядком обжалования. Наконец, сама Палата лордов также должна была одобрить прямое направление жалобы. ${ }^{20}$

Однако, британские политики и парламентарии в $\mathrm{XX}$ в. так и не решились законодательно устранить главное противоречие, заключавшееся в совмещении Палатой лордов законотворческих и судебных функций, явление немыслимое для парламентов других демократических стран. Впрочем, анализ принятых в конце XIX - XX вв. актов показывает, что стремление положить со временем конец этому вопиющему нарушению принципа разделения властей всё же прослеживалось. Об этом, в частности, свидетельствует то что, право рассматривать судебные дела от имени Палаты лордов было вручено узкой группе специально назначенных монархом профессиональных высококвалифицированных юристов. После этого говорить об исполнении судебных функций верхней палатой Парламента можно было лишь формально. Примечательно, что даже при официальном утверждении палатой принятых ординарными лордами по апелляциям решений, как правило, в зале присутствовали только пэры-судьи.

Наконец, нормы и положения большинства принятых в XX в. законов, совершенно очевидно, указывают на то, что право Палаты лордов рассматривать апелляции по уголовным и гражданским делам воспринималось как исключительный способ пересмотра решений нижестоящих судов. Приоритетной же задачей пэров-судей считалось не исправление судебных ошибок, допущенных в отношении конкретных лиц, а правотворческая деятельность. Палата лордов, при осуществлении своих судебных полномочий, должна была соз-

${ }^{20}$ Administration of Justice Act 1969 // URL: http://www. legislation.gov.uk/ukpga/1969/58/pdfs/ukpga_19690058_en.pdf давать, корректировать, разъяснять или отменять нормы прецедентного права, необходимые для успешного функционирования английской судебной системы в целом.

Вместе с тем, совмещение законотворческих и судебных полномочий в руках одних и тех же людей вызывало нарастающую критику, как в британском обществе, так и в профессиональных и экспертных кругах. ${ }^{21}$ Серьезным импульсом для изменения подобного положения дел стало начало в конце XX в. масштабных конституционных преобразований, инициированных лейбористским правительством Т. Блэра, и предусматривавших в том числе и реформирование Палаты лордов. В рамках комплексной и поэтапной модернизации планировалось изменить как принципы формирования состава верхней палаты Парламента, так и ее функции.

Одним из значимых шагов на этом пути стало принятие в 2005 году Акта о конституционной реформе, предусматривавшего в полном соответствии с принципом разделения властей передачу судебных полномочий Апелляционного комитета Палаты лордов - Верховному суду Соединенного королевства. Этот новый институт начал работу с 1 октября 2009 г., а в первый его состав вошли все 12 ординарных лордов по апелляциям, которые сохранили при этом статус пожизненных пэров, но утратили возможность участвовать в голосованиях в верхней палате. В законе предусмотрено, что кандидатуры новых судей для работы в Верховном суде будет отбирать специальная отборочная комиссия из лиц занимающих высшие судебные должности, имеющих не менее чем пятнадцатилетний стаж работы барристером и представляющих все исторические провинции королевства. Назначать же их на должности будет монарх по рекомендации премьер министра. ${ }^{22}$ Бесспорно, что этот закон стал важным этапом на пути к более четкому разграничению полномочий между основными вервями власти в Великобритании. Он устранил саму возможность обвинений в том, что британские судьи вершат правосудие на основе законов, которые они сами и принимают.

Вместе с тем, обращает на себя внимание, что столь важная модернизация была проведена в клас-

${ }^{21}$ Constitutional Reform: A Supreme Court for the United Kingdom. - L., 2003. - 10-13.

22 Constitutional Reform Act 2005 // URL: http://www. legislation.gov.uk/ukpga/2005/4/pdfs/ukpga_20050004_en.pdf 
сических английских традициях, максимально осторожно без радикальной ломки прежней системы. По сути, членов Апелляционного комитета Палаты лордов переместили из Вестминстерского дворца в Мидлсексскую ратушу, дали новое название и в целом сохранили основные полномочия. Британские политики не стали разрушать формировавшуюся в течение длительного времени систему, логично вытекавшую из специфики английского права. Они аккуратно устранили наиболее вопиющее ее несоответствие с современными понятиями демократии и бережно сохранили те ее элементы, которые способны эффективно функционировать.

\section{Библиография:}

1. Арчер П. Английская судебная система. - М., 1959.

2. Access To Justice Act 1999 // URL: http://www. legislation.gov.uk/ukpga/1999/22/pdfs/ukpga_19990022_en.pdf(13.01.2013)

3. Administration of Justice (Appeals) Act 1934 // URL: http://www.legislation.gov.uk/ukpga/1934/40/pdfs/ ukpga_19340040_en.pdf (07.01.2013)

4. Administration of Justice Act 1960 // URL: http:// www.legislation.gov.uk/ukpga/1960/65/pdfs/ukpga_19600065_en.pdf (07.01.2013)

5. Administration of Justice Act 1968 // URL: http:// www.legislation.gov.uk/ukpga/1968/5/pdfs/ukpga_19680005_en.pdf (07.01.2013)

6. Administration of Justice Act 1969 // URL: http:// www.legislation.gov.uk/ukpga/1969/58/pdfs/ukpga_19690058_en.pdf (07.01.2013)

7. Appellate Jurisdiction Act 1876 // URL: http:// www.legislation.gov.uk/ukpga/1876/59/pdfs/ukpga_18760059_en.pdf (21.12.2012)
8. Appellate Jurisdiction Act 1947 // URL: http:// www.legislation.gov.uk/ukpga/1947/11/pdfs/ukpga_19470011_en.pdf (07.01.2013)

9. Constitutional Reform Act 2005 // URL: http:// www.legislation.gov.uk/ukpga/2005/4/pdfs/ukpga_20050004_en.pdf(13.01.2013)

10. Constitutional Reform: A Supreme Court for the United Kingdom. - L., 2003.

11. Courts and Legal Services Act 1990 // URL: http:// www.legislation.gov.uk/ukpga/1990/41/contents (13.01.2013)

12. Criminal Appeal Act 1968 // URL: http://www. legislation.gov.uk/ukpga/1968/19/pdfs/ukpga_19680019_en.pdf (07.01.2013)

13. Criminal Justice Act $1948 / /$ URL: http://www.legislation.gov.uk/ukpga/1948/58/pdfs/ukpga_19480058_ en.pdf (07.01.2013)

14. House of Lords Briefing. The Judicial Work of the House of Lords. - L., 2005.

15. Ingman T. The English Legal Process. - Blackstone, 1996.

16. Judicial Pensions and Retirement Act 1993 // URL: http://www.legislation.gov.uk/ukpga/1993/8/pdfs/ ukpga_19930008_en.pdf (13.01.2013)

17. Oonagh G. and Nerys D. Impeachment. - L., 2011.

18. Powell J.E. Wallis K. The House of Lords in the Middle Ages. - L., 1968.

\section{References (transliteration):}

1. Archer P. Angliyskaya sudebnaya sistema. - M., 1959.

2. Ingman T. The English Legal Process. - Blackstone, 1996.

3. Oonagh G. and Nerys D. Impeachment. - L., 2011.

4. Powell J.E. Wallis K. The House of Lords in the Middle Ages. - L., 1968. 